\title{
It's not only what you say but "how" you say it: linguistic styles and ICOs success
}

\author{
Eleonora Monaco 1,40000-0002-5782-2596](corresponding author), Gianni Onesti ${ }^{20000-0002-2621-3536], ~}$ \\ Diogo Cruz ${ }^{1}$, Pierangelo Rosati ${ }^{3,4[0000-0002-6070-0426]}$ \\ ${ }^{1}$ Universidade Católica Portuguesa, Católica Porto Business School, Rua de Diogo Botelho \\ 1327, 4169-005, Porto, Portugal \\ emonaco@porto.ucp.pt \\ ${ }^{2}$ University of G. d'Annunzio, Department of Neuroscience and Imaging, Chieti, Italy \\ ${ }^{3}$ Irish Institute of Digital Business, DCU Business School, Glasnevin, Dublin, Ireland \\ ${ }^{4}$ European Capital Markets CRC, Via Luigi Polacchi 11, 66100, Chieti, Italy
}

\begin{abstract}
Digital technologies have created new alternative sources of entrepreneurial finance that create significant opportunities for start-ups and entrepreneurs. Among them, Initial Coin Offerings (ICOs) have attracted significant attention from the start-up community and from investors. Despite all the hype around ICOs and the growing number of new token offerings being launched on a daily basis, little is known about the characteristics of successful ICOs. This study aims to fill this gap in the literature by exploring whether and how the linguistic styles adopted in the white paper affects the success of an ICO as measured by the actual amount raised by the offering. Our results are based on a primary dataset of 131 ICOs completed between June 2017 and October 2018. Our results suggest that the use of precise language is positively associated with the amount funded while the use of a concrete language and more numerical terms is negatively associated with the amount funded. This study contributes to the growing literature on ICOs by providing novel insights into the role of the communication strategy adopted by token issuers.
\end{abstract}

Keywords: Initial Coin Offerings, ICOs, Entrepreneurial Finance, Linguistic styles.

\section{Introduction}

The increasing adoption of digital technologies has significantly transformed the way companies conduct their business, how they engage with different stakeholders, and how they raise funds $[40,43]$. In recent years, a number of new sources of entrepreneurial finance have emerged providing start-ups with an unprecedented number of alternative channels to access capital and to finance their expansion [40]. Crowdfunding is probably the most known source of alternative finance for start-ups and can be defined as an online open call for the provision of financial resources from a group of 
individuals or organisations in the form of donation, or in exchange for future access to the product or some form of reward [6, 41].

The volume of capital put through crowdfunding platforms has been growing at a double-digit growth rate for a number of years [62]. The main reasons behind this success can be reconducted to three key features of online crowdfunding namely, the reduction of geographical and physical barriers to funding, the low barrier to entry in terms of minimum investment, and the possibility to attract funders who are not (or not only) driven by financial incentives allowing companies to potentially create a community around their project [2].

More recently, developments in blockchain technology have opened opportunities for bringing the idea of crowdfunding to a new level through tokenization. Initial token offerings, mostly referred to as Initial Coin Offerings (ICOs), are, in their essence, fully disintermediated and unregulated crowdfunding campaigns based on blockchain-based smart contracts $[1,40]$. Even though ICOs represent a recent phenomenon, more than US $\$ 31$ billion has been raised through ICOs since 2013 [53].

Despite to the fact that ICOs have attracted growing interest from researchers, investors, entrepreneurs and regulators, little is still known about the dynamics of ICOs from an entrepreneurial finance perspective and about the characteristics of those companies that successfully leverage ICOs for getting their project off the ground [20].

One of the main issues for potential funders is related to the embedded risk and the information asymmetry typically associated with investing in a new project $[9,63]$. In order to reduce information asymmetry, entrepreneurs typically tend to disclose more [information to potential investors [23]. However, the signalling theory [11, 56] suggests that what is disclosed is as important as how information is communicated as the actions undertaken by the project promoter(s) as it can send important "signals" to potential funders $[13,49]$. This suggests that both the communication styles and the amount of information disclosed can reduce information asymmetry and potentially improve investors' attitude toward an ICO therefore increasing the likelihood of success $[11,57]$.

Recent studies on the determinants of ICOs success (see, for example, [1, 20, 21]) have mostly focused on various characteristics of token offerings. However, none of these studies have explored whether and how the linguistic style (i.e. how the information is communicated) affects the probability of success of ICOs campaigns.

Our study aims to fill this gap by analysing the effect of the linguistic style adopted in the white papers of 133 ICOs that were completed between June 2017 and October 2018 on the amount raised. The linguistic styles are analysed in term of traditional language components, the use of standard linguistic dimensions (e.g., word count), tone of communication, function words (i.e., those that primarily serve a grammatical function) and words that refers to cognitive styles [50,52].

In line with our predictions, our results suggest that the linguistic style adopted in the white paper significantly affects the amount raised by ICOs. Specifically, our study highlights the need to pay attention not only to the "quantity" of the disclosure but also 
to its "quality" suggesting that specific linguistic styles boost the likelihood of success of an ICO.

The rest of this paper is organised as follows. In Section 2, we present prior literature on ICOs and on the role of information asymmetry in the fundraising process. In Section 3, we present the methodology and the data used in this study. Section 4 presents the results of the empirical analysis, while in Section 5 we discuss the results, research limitations, and suggest avenues for future research.

\section{$2 \quad$ Literature review}

\subsection{Initial Coin Offering}

Initial Coin Offerings can be defined as open calls for funding promoted by organisations, companies, and entrepreneurs to raise capital (mostly through cryptocurrencies) in exchange for a token that can be used in the future to obtain access to products or services or sold online in the secondary market $[1,40]$.

ICOs can be seen as the combination of crowdfunding and blockchain technology. While the former has flipped the investment-to-investor ratio typical of start-up financing and has made the idea of peer-to-peer investment possible, the latter has somewhat simplified the start-up financing ecosystem by combining asset tokenisation and disintermediation. The concept of tokenization per se is not new in capital markets. In fact, physical and digital tokens have been around for a long time (e.g., currencies, creditnotes, equities, bonds etc.). In this context, the main novelty introduced by blockchain is the possibility to exchange digital tokens securely and in a fully disintermediated way [46].

Deloitte [15] highlights four key benefits associated with asset tokenization: (1) greater liquidity as tokenization allows traditionally less liquid assets to be traded on secondary markets; (2) faster and cheaper transactions thanks to the automation typical of smart contracts ${ }^{1} ;(3)$ increased transparency as the rights and responsibilities of the token holder are scripted within the token itself; and (4) lower barrier to entry into large scale investment thanks to a lower minimum investment and shorter investment periods.

There are four main types of tokens that can be built onto a blockchain and offered to investors [58]: (1) payment tokens which are essentially cryptocurrencies and can only be used as means of payment; (2) utility tokens which provide digital access to a digital application or service typically (but not necessarily) built on top of a blockchain; (3) asset tokens which represent assets such as an entitlement to dividends or interest

1 Smart contracts can be defined as "digital programs based on a blockchain consensus architecture that automatically implement their internal logic as certain preconditions are met, and which are also able to prevent unauthorised changes of their internal logic as a result of their decentralised nature" [36, p. 7]. 
payments and are somewhat similar to traditional securities; and (4) hybrid tokens which may combine different aspects of the other three types of tokens.

Tokens offered via an ICO are typically of the second type. As such, they do not qualify as securities and fall outside traditional regulatory frameworks [45]. The lack of clear regulation may be attractive for both project promoters and investors as there is less legal burden attached to this type of offerings, but it makes ICOs a controversial channel for raising capital due to the large presence of scams and the lack of investor protection $[9,24,45]$.

\subsection{The determinants of ICOs' success}

Different measures of ICO success have been adopted in the literature such as hard or soft cap targets, token trading and amount raised [1,24].

Token offerings can be used to finance (potentially) any kind of project, and they can be customised to meet the specific objectives of the founders and the requirements of target investors. Fridgen et al. [21] propose a taxonomy, that includes 23 relevant dimensions encompassing 62 characteristics to categorise the most common ICO archetypes. Several studies have explored the impact of some of these characteristics on ICOs success. Among the main characteristics, the size of the founding team has been found being positively associated with ICOs' success $[1,4,39]$. Other studies also suggest that utility tokens are more likely to attract funds compared to security tokens [20, $24,25]$. Interestingly though, empirical evidence seems to suggest that most utility tokens are actually purchased for speculative reasons rather than for future use [31]. Similarly, Lee et al. [37] find a positive relationship between the rating provided by thirdparty platforms ${ }^{2}$ and the likelihood of success.

ICOs may also accept investments only from particularly countries or specific investors. Amsden and Schweizer [4] and Fisch [20] highlight how the lack of clear regulatory frameworks in some countries represents an important factor that influences the growth of this fundraising mechanism.

A number of regulators around the world have been trying to regulate token offerings in recent years in order to establish clear disclosure requirements and more protection for investors. Despite the effort undertaken so far, ICOs still remain characterised by a strong information asymmetry, opaqueness and all the risks typically associated with early-stage start-ups [1,55].

2 Some token trading and market intelligence platforms provides a list of current and upcoming ICOs and assign them a rating based on their perceived quality, riskiness etc. For example, the Icobench.com website is one the main tracking list of ICOs that incorporates a dataset with more than 5,725 ICOs [27]. 


\subsection{Linguistic style, information asymmetry and investors' perception}

Information asymmetry often represent a major barrier to funding for start-ups and young companies $[11,44]$. Most of the time, investors can only rely on a very limited set of information disclosed by the founding team who need to communicate effectively to convince funders about their legitimacy and potential $[12,38]$.

When it comes to token offerings, the white paper associated with a project is the main source of information. However, the extent, type, and quality of information disclosed in these documents tends to vary significantly from one project to another mostly due to the lack of clear disclosure requirements. This may ultimately result in suboptimal investment decisions or lower investments overall [3].

Prior studies leverage the signalling theory $[11,56]$ to explore the fundamental role of communication strategy (i.e. what and how information is disclosed) in reducing information asymmetry. Particularly interesting in the context of this study are those studies that focus on crowdfunding. Agrawal et al. [2], Davis et al. [14], Younkin and Kaskooli [61], and Di Pietro et al. [19] for example, have focused on the description of crowdfunding projects and their role in providing "signals" about the quality of the project to potential investors (e.g., quality of product, social networks, human capital of the entrepreneur etc.).

Parhankangas and Renko [49] focus more on how information is presented to investors and examine the relationship between the style of verbal communication and campaign success. The authors complement the signalling theory with the language expectancy theory $[7,8]$ which suggests that "by observing language behaviours, people develop expectations concerning appropriate communication styles employed by others and themselves" [49, p. 218]. Their results suggest that linguistic styles that make information more accessible and understandable and increase the perceived reliability of the promoters to the crowd are positively related to the likelihood of success of social campaigns but hardly matter for more commercial campaigns.

The literature on the relationship between linguistic styles and the success of crowdfunding campaigns is still quite limited. However, additional evidence on such a relationship is provided by Kaminski and Hopp [29] who demonstrate that linguistic styles that aim to trigger excitement, and are more inclusive, are better predictors of campaign success than firm-level determinants. Similarly, Anglin et al. [5] show that positive narratives and passion have a positive effect on the likelihood of success of a campaign.

Prior studies provide interesting insights into four main types of linguistic style and their relationship with investors' perception and funding success. Specifically, information communicated using a more concrete language are easier to process and to remember $[42,48,54]$. The use of more precise language instead communicates transparency and reliability [22, 28, 32]. Recent psychological research also suggests that people are more prone to help and participate in different initiatives if the language used evokes emotions and is more interactive [16, 17, 33, 54]. Finally, language that communicates psychological distancing (i.e. frequent use of the first person) may be perceived negatively in the context of crowdfunding or token offerings where potential investors may also invest to become part of a community $[47,60]$. 
While several studies have investigated the implications of different linguistic styles on crowdfunding success and other business outcomes, no evidence has been provided so far about their impact on ICOs success. Our study aims to fill this gap in the literature by answering the following research question:

RQ: How does the linguistic style adopted in the white paper affect the amount raised by ICOs?

\section{$3 \quad$ Sample and Methodology}

We compiled our sample starting from a list of 231 ICOs completed between June 2017 and October 2018 as reported on Coindesk ${ }^{3}$. Different characteristics of each ICO were extracted from the white paper, the project website or from other publicly available data sources collected (e.g., ICObench, CoinMarketCap etc.). Despite the considerable effort in terms of data collection, several ICOs had to be excluded from our dataset due to missing data or because the white paper was no longer available. Our final sample included 133 ICOs.

In order to answer our research question, we employed the following OLS regression model:

$$
\begin{aligned}
\log _{(\text {Amount Raised })_{i}=} & \alpha+\beta_{1} \text { Concrete }_{i}+\beta_{2} \text { Precise }_{i}+\beta_{3} \text { Interactive }_{i}+ \\
& +\beta_{4} \text { Psych Distancing }_{i}+\beta_{5} \text { Numerical Terms }_{i}+ \\
& +\beta_{6} \text { Tone }_{i}+\beta_{7} \text { Word Count }_{i}+ \\
& +\beta_{8} \text { Pages White Paper }_{i}+\beta_{9} \text { ICO Size }_{i}+ \\
& +\beta_{10} \text { Utility }_{i}+\beta_{11} \text { ICObench Rating }_{i}+ \\
& +\beta_{12} \text { Tax Haven }_{i}+\beta_{13} \text { Github }_{i}+ \\
& +\beta_{14} \% \text { Tokens Offered }_{i}+\varepsilon_{i}
\end{aligned}
$$

Our dependent variable (i.e. our measure of success) is the natural logarithm of the amount raised. The model also includes two groups of independent variables: (1) our measures of different linguistic styles that were computed using the Linguistic Inquiry and Word Count (LIWC) software [49], and (2) other ICOs' characteristics [1, 20, 21].

Concrete is calculated as the sum of number of articles (i.e., "a", "an", and "the"), prepositions (e.g., "to", “with", “above”) and quantifiers (e.g., "many”, “few”, "a lot”) [35]. Precise is the analytical thinking score as calculated by LIWC which captures the degree to which people use words that suggest formal, logical, and hierarchical thinking patterns [51]. Interactive is equal to the number of questions reported in the text [49]. Psych Distancing is calculated using the frequency of the use of the first person singular ("I") and negative emotions [30, 59,60]. Numerical terms is equal to the frequency of words that refer to numbers (e.g., "second", "third", "thousand", "million"). Tone is computed by LIWC and summarises the presence of both positive and negative

\footnotetext{
${ }^{3}$ https://www.coindesk.com/ico-calendar
} 
emotions. A Tone score lower (higher) than 50 indicates a negative (positive) tone [10]. We also control for the overall number of words (Word Count) included in the white paper and the corresponding number of pages (Pages White Paper).

Following prior studies in the entrepreneurial finance literature, we control for several ICOs' characteristics that have been found to be associated with their success. ICO Size is the target amount of the ICO. Utility is a dummy variable equal to 1 if the token offered in the ICO is a utility token, and 0 otherwise. ICObench Rating is included to control for the overall perceived quality of each $\mathrm{ICO}^{4}$ and ranges from 0 (low quality) to 5 (high quality). Tax Haven is a dummy variable equal to 1 if an ICO is launched from a country with very low tax rates $[4,18]$, and 0 otherwise. Github is a dummy variable equal to 1 if the code associated with the proposed solution is available on Github, and 0 otherwise. Finally, we control for the percentage of tokens offered to the public (\% Token Offered). In fact, most of the companies avoid selling the total amount of tokens issued. Previous research argues that entrepreneurs' willingness to invest in their own venture indicates higher commitment and represents a signal of higher quality $[20,26]$.

\section{$4 \quad$ Results}

Table 1 reports the descriptive statistics for the variables included in our model. On average, the 133 ICOs in our dataset raised $\$ 6.96$ million each with a maximum funding of $\$ 4.1$ billion (EOS) and a minimum of $\$ 0.11$ million (GoHelpFund). The linguistic style that reports the highest average score is Precise (average score 95.40) suggesting that the text of the white papers tends be highly analytical with complex and organised concepts [51]. The average value of Tone is equal to 66.02 (median 65.31) suggesting that white papers tend to convey more positive than negative emotions. However, there seems to be some variation in the dataset as some papers show an extremely positive tone (maximum value of 96.8) while others report a negative tone (minimum of 36.84). The variable Concrete report an average value of 22.80 with a maximum value of 31.98 . This may be somewhat surprising as one would expect to see a higher value (i.e., a more concrete language). The descriptive statistics of both Psych Distancing and Interactive report average values less than 1 .

Similarly, to previous studies (e.g., [20]), token issuers offer, on average, 52 percent of the total amount of tokens for sale with some issuers offering only 2 percent and others offering 100 percent.

Finally, it is worth noting that only 89 percent of the ICOs in our sample issued utility tokens, 17 percent are based in countries that have been classified as tax havens, and 62 percent have made the source code of the proposed solution available on Github.

4 ICObench is considered one of the main sources of information for common investors [37]. 
Table 1. Descriptive Statistics and Data Sources

\begin{tabular}{|c|c|c|c|c|c|c|}
\hline Variables & Mean & SD & Min. & Median & Max. & Data source \\
\hline \multicolumn{7}{|l|}{ Dependent variable } \\
\hline Amount raised $(\log )$ & 1.94 & 1.32 & -2.21 & 8.00 & 8.31 & Icobench.com \\
\hline \multicolumn{7}{|l|}{ Independent variables } \\
\hline \multicolumn{7}{|l|}{ Linguistic styles } \\
\hline Concrete & 22.80 & 3.67 & 2.68 & 22.97 & 31.98 & White papers \\
\hline Precise & 95.40 & 2.04 & 86.53 & 95.84 & 99 & White papers \\
\hline Interactive style & 0.70 & 0.22 & 0.03 & 0.69 & 1.38 & White papers \\
\hline Psych Distancing & 0.74 & 0.35 & 0.08 & 0.7 & 2.3 & White papers \\
\hline Numerical terms & 5.21 & 2.75 & 2.16 & 4.66 & 21.15 & White papers \\
\hline Tone & 66.02 & 13.34 & 36.84 & 65.31 & 96.8 & White papers \\
\hline Word Counts & 9,765 & 4,704 & 551 & 9,075 & 26,276 & White papers \\
\hline Pages White papers & 40.66 & 16.78 & 8 & 40 & 99 & White papers \\
\hline \multicolumn{7}{|c|}{ Characteristics of ICOs campaigns } \\
\hline ICO Size & 43.77 & 363.33 & 0.03 & 9.02 & 4,200 & Coindesk.com \\
\hline Utility & 0.89 & 0.32 & 0 & 1 & 1 & Multiple* \\
\hline ICObench Rating & 3.50 & 0.67 & 0 & 3.6 & 4.6 & Icobench.com \\
\hline Tax Haven & 0.17 & 0.38 & 0 & 0 & 1 & Multiple* \\
\hline Github & 0.62 & 0.49 & 0 & 1 & 1 & Multiple* \\
\hline$\%$ Tokens offered & 0.52 & 0.20 & 0.02 & 0.5 & 1 & Multiple* \\
\hline
\end{tabular}

*Multiple sources: www.icobench.com, www.icodrops.com, www.tokenmarket.com, www.coindesk.com.

In order to make sure that multicollinearity does not bias the results of regression, we performed a correlation analysis. The results ${ }^{5}$ show only moderate or low correlations suggesting that multicollinearity should not be an issue in our research setting.

Table 2 presents the results of our regression analysis. All models are estimated using heteroscedasticity robust standard errors. Specifically, we ran two separate models. A first model (Model A) which only includes the variables related to the linguistic styles, and a second model (Model B) which also includes the main determinants of ICOs' success as suggested by prior studies (e.g., [4, 20, 21]).

For each regression, we also calculate the average variance inflation factors (VIFs). All VIFs were below the critical value of 5 providing further assurance that multicollinearity is not affecting our research design [34].

The results in Table 2 show that precise language (Precise) is positively associated with the amount raised. This is in line with Parhankangas and Renko [49] who find that precise language is positively associated with the likelihood of campaign success. Surprisingly, Concrete is negatively associated with the amount raised by ICOs. This contrasts with the findings of Parhankangas and Renko [49] and may be due to differences in the type of investor that are attracted by ICOs compared to equity crowdfunding.

\footnotetext{
${ }^{5}$ Available from the authors upon request.
} 
Table 2. OLS Regression Results

\begin{tabular}{|c|c|c|c|c|}
\hline \multirow[b]{2}{*}{ Variables } & \multicolumn{2}{|c|}{ Model A } & \multicolumn{2}{|c|}{ Model B } \\
\hline & Coeff. & $(\mathrm{SE})$ & Coeff. & $(\mathrm{SE})$ \\
\hline \multicolumn{5}{|l|}{ Linguistic styles } \\
\hline Concrete & $-0.048^{*}$ & $(0.024)$ & $-0.059 *$ & $(0.030)$ \\
\hline Precise & $0.148 * *$ & $(0.057)$ & $0.168 * * *$ & $(0.058)$ \\
\hline Interactive Style & 0.479 & $(0.597)$ & 0.298 & $(0.556)$ \\
\hline Psych Distancing & -0.308 & $(0.375)$ & -0.405 & $(0.314)$ \\
\hline Numerical Terms & $-0.127 *$ & $(0.068)$ & $-0.142 *$ & $(0.073)$ \\
\hline Tone & -0.011 & $(0.011)$ & -0.010 & $(0.010)$ \\
\hline Word Count & -0.000 & $(0.000)$ & -0.000 & $(0.000)$ \\
\hline Pages White Papers & 0.008 & $(0.013)$ & $0.019 * *$ & $(0.010)$ \\
\hline \multicolumn{5}{|c|}{ Characteristic of ICOs campaigns } \\
\hline ICO Size & & & $0.002 * * *$ & $(0.000)$ \\
\hline Utility & & & -0.015 & $(0.421)$ \\
\hline ICObench Rating & & & 0.248 & $(0.171)$ \\
\hline Tax Haven & & & 0.362 & $(0.250)$ \\
\hline Github & & & -0.152 & $(0.252)$ \\
\hline$\%$ Tokens offered & & & 0.864 & $(0.549)$ \\
\hline Adj. $\mathrm{R}^{2}$ & 0.022 & & 0.240 & \\
\hline Observations (ICOs) & 133 & & 133 & \\
\hline
\end{tabular}

$* \mathrm{p}<0.1 ; * * \mathrm{p}<0.05 ; * * * \mathrm{p}<0.01 ;$ two-tailed test.

The coefficients for Interactive, Psych Distancing and Tone are not statistically significant, suggesting that they do not affect ICOs' success. The presence of Numerical Terms in the text instead is negatively associated with to the amount funded. The coefficient of Word Count is not statistically significant while the number of pages is positively related to the amount founded. The number of pages in the white paper may proxy for the amount of information disclosed therefore this result may suggest that the quantity of information disclosed to the investors positively affect the amount raised by the ICO. Turning our attention to other ICOs characteristics, the results reveal that only the scale of the ICO is positively related to the amount raised. The coefficients of all other variables are not statistically significant. 


\section{$5 \quad$ Discussion and Conclusion}

Our study leverages the signalling theory and the language expectancy theory to explore the relationship between the linguistic style adopted in the white papers and the amount raised by ICOs. As such, this study contributes to the growing strand of entrepreneurial finance literature that focuses on ICOs by providing novel insights on the importance of the style of communication adopted by token issuers.

Our results suggest that the use of more precise language and the disclosure of a larger volume of information in the white paper has positive effects on the amount raised by the ICO. On the contrary, the use of more concrete language and numerical terms seems to have a negative effect on the amount raised.

The results of our study may be of interest for both academics and practitioners. Academics may benefit from novel insights on the importance of the linguistic style in the context of ICOs. Future research, for example, may explore additional characteristics of the text presented in the white paper, or explore the characteristics of the messages posted on various social media platforms. Future research may also compare ICOs and Security Token Offerings (STOs) to see whether major differences emerge.

Our findings may also be of interest for practitioners as they may provide them with clear guidelines in terms how to disseminate information to investors, and how to build legitimacy and trust around the proposed project. This is particularly relevant in the context of ICOs where new projects are promoted on a daily basis and where the large number of scams and low-quality projects that have been promoted in recent years may have made investors particularly suspicious.

\section{References}

1. Adhami, S., Giudici, G. and Martinazzi, S.: Why do business go crypto? An empirical analysis of Initial Coin Offerings. Journal of Economic and Business 100, 64-75 (2018). doi:10.1016/j.jeconbus.2018.04.001

2. Agrawal, A., Catalini, C., and Goldfarb, A. The geography of crowdfunding. National Bureau of Economic Research (2011). doi: 10.3386/w16820

3. Ahlers, G., Cumming, D., Guenther, C., Schweizer, D.: Signaling in Equity Crowdfunding. Entrepreneurship Theory and Practice 39(4), 955-980 (2015). doi:10.1111/etap.12157

4. Amsden, R., Schweizer, D.: Are Blockchain Crowdsales the New "Gold Rush"? Success Determinants of Initial Coin Offerings. SSRN Electronic Journal (2018). doi:10.2139/ssrn.3163849

5. Anglin, A. H., Short, J. C., Drover, W., Stevenson, R. M., McKenny, A. F., Allison, T. $\mathrm{H}$. The power of positivity? The influence of positive psychological capital language on crowdfunding performance. Journal of Business Venturing 33(4), 470-492 (2018).

6. Belleflamme, P., Lambert, T., Schwienbacher, A., Crowdfunding: Tapping the right crowd. Journal of business venturing 29(5), 585-609 (2014).

7. Burgoon, M., Denning, V.P., Roberts, L.: Language expectancy theory. In: Dillard, J.P., Pfau, M. (eds) The persuasion handbook: Developments in theory and practice. pp. 117136. SAGE Publications, Inc. (2002). doi: 10.4135/9781412976046.n7. 
8. Burgoon, M., Miller, G.R.: An Expectancy Interpretation of Language and Persuasion. In: Giles, H., St. Clair, R.N. (eds.) Recent Advances in Language, Communication and Social Psychology. Lawrence Erlbaum Associates Ltd., London, UK, pp. 199-229 (1985).

9. Chen, Y.: Blockchain Tokens and the Potential Democratization of Entrepreneurship and Innovation. Business Horizons. 61, 567-575. (2018). doi: 10.1016/j.bushor.2018.03.006.

10. Cohn, M.A., Mehl, M.R., Pennebaker, J.W.: Linguistic Markers of Psychological Change Surrouding September 11, 2001. Psychological Science. 15 (10), 687-693 (2004). doi: 10.1111/j.0956-7976.2004.00741.x.

11. Connelly, B., Certo, T., Ireland, R., Reutzel, C.: Signaling Theory: A Review and Assessment. Journal of Management. 37(1), 39-67 (2011). doi: $10.1177 / 0149206310388419$.

12. Cornelissen, J. P., Clarke, J. S.: Imagining and rationalizing opportunities: Inductive reasoning and the creation and justification of new ventures. Academy of Management Review, 35(4) (2010). doi: 10.5465/amr.35.4.zok539.

13. Courtney, C., Dutta, S., Li, Y. Resolving information asymmetry: Signaling, endorsement, and crowdfunding success. Entrepreneurship Theory and Practice, 41(2), 265-290 (2017).

14. Davis, B., Hmieleski, K., Webb, J., Coombs, J.: Funders' positive affective reactions to entrepreneurs' crowdfunding pitches: The influence of perceived product creativity and entrepreneurial passion. Journal of Business Venturing. 32, 90-106 (2017). doi: 10.1016/j.jbusvent.2016.10.006.

15. Deloitte. The tokenization of assets is disrupting the financial industry (2018).

16. Dickert, S., Sagara, N., Slovic, P.: Affective Motivations to Help Others: A Two-stage Model of Donation Decisions. Journal of Behavioral Decision Making 24(4), 361-376 (2011). doi: 10.1002/bdm.697.

17. Dickert, S., Slovic, P.: Attentional mechanisms in the generation of sympathy. Judgment and Decision Making 4(4), 297-306 (2009).

18. Diemers, D., Arslanian, H., McNamara, G., Dobrauz G. and Wohlgemuth, L.: Initial Coin Offering: A strategic perspective, PWC report (2018).

19. Di Pietro, F., Grilli, L., Masciarelli, F.: Talking About a Revolution? Costly and Costless Signals and The Role of Innovativeness in Equity Crowdfunding. Journal of Small Business Management (2020). doi: 10.1080/00472778.2020.1816435.

20. Fisch, C.: Initial coin offerings (ICOs) to finance new ventures. Journal of Business Venturing. 31(1), 1-22 (2018). doi: 10.1016/j.jbusvent.2018.09.007

21. Fridgen, G., Regner, F., Schweizer, A. and Urbach, N.: Do not Slip on the Initial Coin Offering (ICO) - A taxonomy for a blockchain enabled form of crowdfunding. Research Paper (2018).

22. Geppert J., and Lawrence J.E.: Predicting Firm Reputation Through Content Analysis of Shareholders' Letter. Corporate Reputation Review. 11(4), 285-307 (2008).

23. Healy, P. M., Palepu, K. G. Information asymmetry, corporate disclosure, and the capital markets: A review of the empirical disclosure literature. Journal of accounting and economics, 31(1-3), 405-440 (2001).

24. Howell, S., Niessner, M., Yermack, D.: Initial Coin Offerings: Financing Growth with Cryptocurrency Token Sales. European Corporate Governance Institute (ECGI) - Finance Working Paper No. 564/2018. (2019). doi: 10.2139/ssrn.3201259

25. Howell, S.: Joint ventures and technology adoption: A Chinese industrial policy that backfired. Research Policy 47(8), 1448-1462 (2018).

26. Huang, W., Meoli, M. and Vismara, S.,: The geography of Initial Coin Offerings. Small Business Economics 55, 77-102 (2020). doi: 10.1007/s11187-019-00135-y 
27. ICObench. https://icobench.com/ (2020).

28. Johnson, W.: People in Quandaries: The Semantics of Personal Adjustment. Harper, New York, NY (1946).

29. Kaminski, J. C., Hopp, C. Predicting outcomes in crowdfunding campaigns with textual, visual, and linguistic signals. Small Business Economics 55, 627-649 (2020). doi: 10.1007/s11187-019-00218-w.

30. Kangas, S.E.N.: What can software tell us about political candidates? A critical analysis of a computerized method for political discourse. Journal of Language and Politics 13(1), 77-97 (2014). doi: 10.1075/jlp.13.1.04kan.

31. Kharif, O.: Only One in 10 Tokens Is in Use Following Initial Coin Offerings. Bloomberg (2017).

32. Knapp, M.L., Hart, R.P., Dennis, H.S.: An exploration of deception as a communication construct. Human Communication Research 1(1), 15-29 (1974). doi:10.1111/j.14682958.1974.tb00250.x

33. Kogut, T., Ritov, I.: The 'Identified Victim' Effect: An Identified Group, or Just a Single Individual?. Journal of Behavioral Decision Making 18(3), 157-167 (2005). doi: 10.1002/bdm.492.

34. Kutner M.H., Nachtsheim C.J., Neter J. and Li W.: Applied linear statistical models. 5th McGraw-Hill. Irwin (2005).

35. Larrimore, L., Jiang, L., Larrimore, J., Markowitz, D., Gorski, S.: Peer to peer lending: the relationship between language features, trustworthiness, and persuasion success. Journal of Applied Communication Research 39(1), 19-37 (2011). doi: 10.1080/00909882.2010.536844

36. Lauslahti, K., Mattila, J., Seppala, T. Smart contracts-How will blockchain technology affect contractual practices?. Etla Reports, (68) (2017).

37. Lee, J., Li, T., Shin, D.: The Wisdom of Crowds in FinTech: Evidence from Initial Coin Offerings. (2018). doi: 10.2139/ssrn.3195877

38. Lounsbury, M., Glynn, M. A.: Cultural entrepreneurship: Stories, legitimacy, and the acquisition of resources. Strategic management journal 22(6-7), 545-564 (2001). doi: 10.1002/smj.188.

39. Lyandres, E., Palazzo, B., Rabetti, D.: Are Tokens Securities? An Anatomy of Initial Coin Offerings. SSRN Electronic Journal (2018). doi: 10.2139/ssrn.3287583.

40. Lynn T., Rosati P.: New Sources of Entrepreneurial Finance. In: Soltanifar M., Hughes M., Göcke L. (eds) Digital Entrepreneurship. Future of Business and Finance. Springer, Cham (2021). doi: 10.1007/978-3-030-53914-6_11.

41. Lynn, T., Rosati, P., Nair, B., Mac an Bhaird, C. Harness the crowd: An exploration of the crowdfunding community on Twitter. In ISBE Annual Meeting 2017 (2017).

42. Marschark, M., and Surian, L.: Concreteness effects in free recall: The roles of imaginal and relational processing. Memory and Cognition 20(6), 612-620 (1992).

43. Matt, C., Hess, T., Benlian, A.: Digital transformation strategies. Business \& Information Systems Engineering, 57(5), 339-343 (2015).

44. Megginson, W.L., Weiss, K.A.: Venture capitalist certification in initial public offerings. Journal of Finance 46(3), 879-903 (1991). doi: 10.1111/j.1540-6261.1991.tb03770.x

45. Momtaz, P. P., Rennertseder, K., Schroeder, H. Token Offerings: A Revolution in Corporate Finance? Journal of Financial Transformation (49) (2019).

46. Nakamoto, S.: Bitcoin: A peer-to-peer electronic cash system (2008). doi:10.2139/ssrn.3440802

47. Newman, M., Pennebaker, J., Berry, D., Richards, J.: Lying Words: Predicting Deception from Linguistic Styles. Personality \& social psychology bulletin. 29(5), 665-675 (2003). doi: 10.1177/0146167203029005010. 
48. Paivio, A.: Dual coding theory: Retrospect and current status. Canadian Journal of Psychology/Revue canadienne de psychologie. 45(3), 255-287 (1991).

49. Parhankangas, A., Renko, M.: Linguistic style and crowdfunding success among social and commercial entrepreneurs. Journal of Business Venturing. 32(2), 215-236 (2017). doi: 32. 10.1016/j.jbusvent.2016.11.001.

50. Pennebaker, J., Chung, C.: Expressive Writing: Connections to Physical and Mental Health. In: Friedman H.S. (ed). The Oxford Handbook of Health Psychology (2012). doi: 10.1093/oxfordhb/9780195342819.013.0018.

51. Pennebaker, J.W.. Chung, C.K., Frazee, J., Lavergne, G.M. and Beaver, D.I.: When Small Words Foretell Academic Success: The Case of College Admissions Essays. PLoS ONE 9(12) (2014).

52. Pennebaker, J.W., Mehl, M.R. and Niederhoffer, K.G. Psychological Aspects of Natural Language Use: Our Words, Our Selves. Annual Review of Psychology 54(1), 547-577 (2003).

53. PwC. 6th ICO / STO Report - A Strategic Perspective (2020).

54. Schwanenflugel, P. J., and Stowe, R. W.: Context availability and the processing of abstract and concrete words in sentences. Reading Research Quarterly 24(1), 114-126 (1989).

55. SEC. 2017: Investor bulletin: initial coin offerings. Retrieved from: https://www.sec.gov/oiea/investor-alerts-and-bulletins/ib_coinofferings.

56. Spence, M.: Job market signaling. In: Diamond, P., Rothschild, M. (eds). Uncertainty in economics, pp. 281-306. Academic Press (1978).

57. Spence, M.: Signaling in Retrospect and the Informational Structure of Markets. American Economic Review 92(3), 434-459 (2002).

58. Tasca, P.: Token-Based Business Models. In: Lynn T., Mooney J., Rosati P., Cummins M. (eds). Disrupting Finance, pp. 135-148. Palgrave Pivot, Cham (2019).

59. Tausczik, Y.R., Pennebaker, J.W.: The psychological meaning of words: LIWC and computerized text analysis methods. Journal of Language and Social Psychology 29(1), 24-54 (2010). doi: 10.1177/0261927X09351676.

60. Toma, C.L., Hancock, J.T.: What lies beneath: the linguistic traces of deception in online dating profiles. Journal of Communication. 62(1), 78-97 (2012). doi: 10.1111/j.14602466.2011.01619.x

61. Younkin, P., Kashkooli, K.: A crowd or a community? Comparing three explanations for the decision to donate to a crowdfunding project. https://funginstitute.berkeley.edu/wpcontent/uploads/2013/11/A_Crowd_Or_Community.pdf (2013).

62. Ziegler, T., Shneor, R. Wenzlaff, K., Wang, W. B. et al.: The Global Alternative Finance Market Benchmarking Report (2020).

63. Zetzsche, D. A., Buckley, R. P., Arner, D.W., Föhr, L.: The ICO Gold Rush: It's a Scam, It's a Bubble, It's a Super Challenge for Regulators. Harvard International Law Journal 63(2) (2019). doi: 10.239/ssrn.3072298 